\title{
MULTIPLE ITERATIONS OF MSLQ VALIDATION: A CONTEMPORARY ASSESSMENT
}

\author{
Catherine Chen, Ball State University, cchen@bsu.edu \\ Sheila M. Smith, Ball State University, smariesmith@bsu.edu
}

\begin{abstract}
It is imperative that institutes of higher education produce self-directed, self-regulated learners who plan their learning goals, monitor and control their learning, and adjust their learning strategies to meet their academic objectives. One of the most widely used instruments to investigate self-regulated learning strategies is the Motivated Strategies for Learning Questionnaire (MSLQ); however, the instrument's latent factor structure and discriminant validity have been questioned. This study collected three iterations of data for Motivation and two iterations of data for Learning Strategies validation. Principal component analysis and confirmatory factor analysis were conducted to investigate the latent factor structure. Convergent and discriminant validity tests were performed to test construct validity. The analyses revealed similar Motivation subscales and items that were consistent with the original subscales, but the modified items did not correspond well with the original Learning Strategies subscales.
\end{abstract}

Keywords: MSLQ, Validity study, Motivation, Learning Strategies, Self-Regulated Learning

\section{INTRODUCTION}

In the 21 st centenary, students are encouraged to perform as self-regulated learners who employ metacognitive strategies, self-motivation, and become behaviorally active participants in their own learning process (Zimmerman, 2001, p. 5). Self-regulated learning (SRL) is often regarded as an event as opposed to an aptitude. When viewed as an aptitude, learners have relatively stable approaches to selecting and managing the strategies they use in learning. Viewed as an event, on the other hand, learners monitor their engagement and learning outcomes and dynamically adjust their use of strategies as the task proceeds (Butler \& Winne, 1995; Pintrich, Smith, Garcia, \& McKeachie, 1991). Pintrich (2004) stated that there were four phases in a SRL conceptual framework: (1) planning and goal setting, (2) monitoring, (3) controlling, and (4) reactions and reflections. In the planning and goal setting phase, learners create a profile of the task, their existing knowledge, and the context. In phase two, learners use their metacognitive awareness to monitor self, the task in hand, and the context. Learners control and regulate their learning effort in phase three, and they reflect and react on themselves, the task, or the context in phase four. The enabling cognitive activity of the four SRL phases was metacognition. Dobrovolny (2006) defined metacognition as the ability to self-assess and self-correct based on that assessment; in other words, metacognition referred to the awareness, knowledge, and control of cognition. SRL can also include time management, regulating one's own physical and social environment, and the ability to control one's effort and attention (Pintrich, 1995; Zimmerman \& Risemberg, 1997). This view supports phases two and three in the SRL framework suggested by Pintrich.

One of the most widely used instruments to assess students' learning strategies is the MSLQ. Based on a self-regulated perspective on student motivation and learning, the questionnaire assesses student motivation and SRL in college students (Pintrich, Smith, Garcia, \& McKeachie, 1991). There are two sections in the MSLQ: A Motivational section with 6 subscales and a Learning Strategies section with 9 subscales. The MSLQ was designed with the flexibility to allow researchers to select sub-section or subscales for their research projects. However, research has revealed concerns about the latent factor structure of the MSLQ. According to Hilpert, Stemien, van der Hoeven Kraft, and Husman (2013), the confirmatory factor analysis (CFA) did not produce a good fit in MSLQ's first development in 1990. An attempted was made to improve the fit in 1993 without success. Credé, and Phillips (2011) reported many relatively low validities for many of the MSLQ scales after a meta-review of the MSLQ from 59 articles representing 19,900 college students. Dunn, Lo, Mulvenon, and Sutcliffe, (2012) suggested further investigation to explore the latent factor structure of both motivation and learning strategies scales. 


\section{Issues in Information Systems}

Volume 18, Issue 3, pp. 149-160, 2017

\section{LITERATURE REVIEW}

Vaculíkova (2016) conducted three rounds of validation study to verify the construct validity and internal consistency of the scales in the Motivation section. A three-subscale Motivation was reported, including Self-Efficacy, Task Value, and Test Anxiety. Hilpert et al. (2013) also suggested a model with three constructs: expectancy, value, and selfregulation. In their model, expectancy contained self-efficacy and control of learning subscales; value consisted of intrinsic goals and task values subscales; and self-regulation had metacognitive regulation and effort regulation subscales. This model was drastically reduced from the original MSLQ with 15 subscales.

In terms of discriminant and convergent validity, Malpass, O'Neil, and Hocevar, (1999) found that the Effort Regulation and Metacognitive Self-Regulation subscales could not be distinguished. Rao and Sachs (1999) provided evidence for a five-factor oblique model; yet, they could not distinguish between strategy use and self-regulation factors and ultimately combined them, using a Method factor as the fifth latent variable. Dunn et al. (2012) thoroughly reviewed many of these problems and provided a recombination of the Metacognitive Self-Regulation and Effort Regulation items that might help future researchers.

MSLQ was initially designed for lecture-type courses. Research showed that when an applied learning approach was involved in a computer course, Peer Learning (Niemczyk \& Savenye, 2001), Critical Thinking (Chalupa, Chen, \& Charles, 2001; Niemczyk \& Savenye, 2001), and Organization (Chalupa, Chen, \& Charles, 2001) all had an inverse relationship with course grades. These findings contradicted the general belief that the use of these cognitively involved strategies should not have hindered their grades. When investigating the relationship between learning strategies and paper-and-pencil test scores and the relationship between learning strategies and computer hands-on computer lab assignment scores, Chen (2002) found that the normal probability plot with test scores as dependent variable met the assumption of normality. However, the normal probability plot for computer hands-on lab assignments showed substantial departures from the diagonal line. These plots suggested that the MSLQ had its limitation in investigating learning strategies in computer hands-on courses. Citing others' work in learning strategies used in different subject areas, Wolters and Pintrich (1998) concluded that "the level of SRL in terms of strategy use can very as a function of subject area differences in classroom context" (p. 43). This statement implied the need to development different versions of the instrument to assess effective learning strategies in different classroom contexts.

\section{PURPOSE OF THE STUDY}

The purpose of this study was to conduct multiple iterations of data collection to perform multiple rounds of analyses to test the latent structure and validity of a modified MSLQ.

\section{RESEARCH METHODOLOGY}

This section describes the original scales in the MSLQ, the steps taken to revise the MSLQ items, the subjects participated in the study, the data collection procedures, and the statistical analyses used.

\section{The Original Scales}

The Motivation section of the original MSLQ consisted of 31 items in six scales: Intrinsic Goal Orientation, Extrinsic Goal Orientation, Task Value, Control of Learning Belief, Self-Efficacy for Learning and Performance, and Test Anxiety. The Learning Strategies section consisted of 50 items in nine scales: Rehearsal, Elaboration, Organization, Critical Thinking, Metacognitive Self-Regulation, Time and Study Environment, Effort Regulation, Peer Learning, and Help Seeking. (Pintrich et al 1991).

\section{The Revisions of the Questionnaire Items}

Two senior instructors, each with more than 20 years of teaching computer-related classes, revised the items to make them more specifically focused on learning computer skills. Two male and two female Information Systems majors 


\section{Issues in Information Systems}

Volume 18, Issue 3, pp. 149-160, 2017

provided feedback on the wording and clarity of the revised items. Based on these students' feedback, minor changes were made. The revised instrument was created using Qualtrics, and responses were scored using a 6-point Likert type scale, from 1 (not at all like me) to 6 (just like me).

\section{Data Collections and Subjects}

Three iterations of data collections were conducted for the Motivation section in spring 2014, spring of 2015, and fall of 2015. Two iterations of data collections were conducted for the Learning Strategies section in spring and fall of 2015. Data were collected in the last week of the semester, prior to the finals exam week. Consent to collect data was obtained from each of the instructors who taught the course, and students were invited to complete the Qualtrics survey posted on their course Blackboard. The online survey included an opening section detailing the purposes of the study, the voluntary nature of their participation, and a request for students' consent.

Students enrolled in seven computer-related classes in the Information Systems and Operations Management Department in a large Midwestern university were invited to participate in this study. Students enrolled in these classes were required to use a minimum of two of the following tools: Word, PowerPoint, Excel, Access, Visio, Project, Visual Basic for Applications (VBA), Microsoft Windows Server 20012, SQL Server 2012, and the Web/Internet. Two-hundred-fifty-six students participated in 2014 spring survey; one-hundred-ninety-nine students participated in 2015 spring survey; and two-hundred-ninety-one students participated in 2015 fall survey. The demographics were very similar among these three groups of students. Majority of the students were male (2014: 66\%, 2015 spring: 65.8\%, 2015 fall: 57.4\%), white (2014: 81.6\%, 2015 spring: 81.4\%, 2015 fall: 90.4\%), and enrolled in the College of Business (2014: 82.8\%, 2015 spring: 87.9\%, 2015 fall: 90\%). The majority of participants were juniors (36.7\%) in 2014, seniors (54.8\%) in 2015 spring, and freshmen (50.5\%) in 2015 fall.

\section{Analysis Approach}

Exploratory factor analysis (EFA) using principal components factor extraction was used to determine if the items in the Motivation section and those in the Learning Strategies section correspond to the respective scales. To ensure that it was appropriate to perform factor analysis on the data, measure of sample adequacy (MSA) statistics were calculated prior to performing the factor analysis (Hair, Black, Babin, Anderson, \& Tatham, 2010).

Validity refers to the degree of adequacy and appropriateness of the interpretations and actions based on the observed scores (Hair et al., 2010; Kane 2001). In this study, confirmatory factor analysis (CFA) was used to investigate the internal validity. A path model was used as a basis for testing convergent validity and discriminant validity. Both convergent and discriminant evidence are fundamental in test validation (Hair et al. 2010), and both are considered subcategories of construct validity. Convergent validity measures constructs that theoretically should be related to each other are, in fact, observed to be related to each other. Discriminant validity, on the other hand, demonstrates measures that should not be related are in reality not related. Following the factor analyses, the internal consistency of reliability was computed using Cronbach's coefficient alphas (Cronbach \& Shavelson, 2004).

\section{FINDINGS}

This section reports the findings of the MSA, EFA, and CFA, as well as the convergent validity and discriminant validity results. The three iterations of data collected for the Motivation section were analyzed separately, and the two iterations of data collected for the Learning Strategies section were analyzed separately as well.

\section{Motivation Section Exploratory Factor Analysis}

The data was subjected to a MSA prior to the EFA. An overall KMO (MSA) of .8 or higher and item MSA of .7 or higher were considered desirable and a MSA of .60 was considered acceptable. Communality values were the variance explained for each item. A low communality suggests that the factor model was not working well for that indicator, and a communality of .5 was desired. For a sample size of approximately 200, a factor loading of .40 was considered significant based on a .05 significance level; for a sample size of approximately 250 , a factor loading of .35 was considered significant (Hair et al., 2010). A more rigorous factor loading of .40 was used in all analyses for this study, although more than 250 subjects participated in two of the three iterations of data collections. In an EFA, cross loading 


\section{Issues in Information Systems}

Volume 18, Issue 3, pp. 149-160, 2017

occurs when a variable has two or more significant factor loadings. After the initial EFA is obtained, researchers usually conduct several iterations of EFA to arrive at the best representation of the data. In general, items with a low MSA or with significant cross loadings were deleted (Hair et al., 2010).

For ease of item identification, abbreviations were used to indicate scales in the MSLQ: Intrinsic Goal Orientation (In), Extrinsic Goal Orientation (Ex), Task Value (TA), Control of Learning Belief (CB), Self-Efficacy for Learning and Performance (SE), and Test Anxiety (TA).

2014 EFA. The initial EFA revealed an overall KMO (MSA) statistic of .894, and all item MSAs exceeded the desired value of .7 with the exception of item 11 (.687). All items exceeded the desirable communality value of .5 with the exception of item 1 (.479) and item 30 (.422). Six factors were extracted with item 29 crossed-loaded. Several trials of EFA were conducted to obtain the best representation of the data. As shown in Table 1, the factor loadings did not correspond well to the original Motivation scales, with the exception of Test Anxiety (TA). The data indicated that Extrinsic Goal Orientation scale did not exist, and Self-Efficacy was loaded in two different factors.

Table 1. Factor Loading-Motivation Scales, 2014

\begin{tabular}{lcclllll}
\hline & \multicolumn{2}{c}{ Factors } & & & \multicolumn{3}{c}{ Factors } \\
\cline { 2 - 3 } \cline { 5 - 6 } Item & $\mathbf{1}$ & & & Item & $\mathbf{3}$ & $\mathbf{4}$ & $\mathbf{5}$ \\
\hline M10_TV & .890 & & & M21_SE & .892 & & \\
M4_TV & .864 & & & M5_SE & .854 & & \\
M27_TV & .795 & & & M31_SE & .800 & & \\
M23_TV & .786 & & & M20_SE & .770 & & \\
M26_TV & .771 & & & M19_TA & & .822 & \\
M17_TV & .728 & & & M28_TA & & .770 & \\
M22_In & .639 & & & M14_TA & & .740 & \\
\hline M6_SE & & .977 & & M3_TA & & .724 & \\
M15_SE & & .876 & & M8_TA & & .675 & \\
M12_SE & & .769 & & M25_CB & & & .861 \\
M16_In & & .654 & & M9_CB & & & .740 \\
M18_CB & & .584 & & & & & \\
M29_SE & & .485 & & & & & \\
\hline
\end{tabular}

2015 Spring EFA. The initial EFA revealed an overall KMO (MSA) statistic of .845, and all item MSAs exceeded the desired value of .7 with the exception of item 16 (.463). All items exceeded the desirable communality value of .5 with the exception of item 13 (.480). Seven factors were extracted with many crossed-loaded items. As with the EFAs conducted for 2014 data, several trials of EFA were conducted to arrive at the best representation of the data. Table 2 illustrates the factor loadings. The factor loadings for 2015 spring data were similar to that of 2014 findings. They did not correspond well to the original Motivation scales, with the exception of Test Anxiety. Extrinsic Goal Orientation did not exist and Self-Efficacy scale was loaded in two different scales, as with data from 2014.

Table 2. Factor Loading-Motivation Scales, 2015 Spring

\begin{tabular}{|c|c|c|c|c|c|c|}
\hline \multirow[b]{2}{*}{ Item } & \multicolumn{2}{|c|}{ Factors } & \multirow[b]{2}{*}{ Item } & \multicolumn{3}{|c|}{ Factors } \\
\hline & 1 & 2 & & 3 & 4 & 5 \\
\hline M27_TV & .887 & & M19_TA & .809 & & \\
\hline M26_TV & .830 & & M8_TA & .800 & & \\
\hline M17_TV & .809 & & M14_TA & .776 & & \\
\hline M23_TV & 7.64 & & M28_TA & .748 & & \\
\hline M22_In & .456 & & M3_TA & .653 & & \\
\hline M21_SE & & .920 & M1_In & & .900 & \\
\hline M5_SE & & .851 & M6_SE & & .700 & \\
\hline M31_SE & & .703 & M15_SE & & .673 & \\
\hline M20_SE & & .678 & M12_SE & & .503 & \\
\hline M29_SE & & .596 & M2_CB & & & .936 \\
\hline & & & $\mathrm{M} 9 \mathrm{CB}$ & & & .541 \\
\hline
\end{tabular}




\section{Issues in Information Systems}

Volume 18, Issue 3, pp. 149-160, 2017

2015 Fall EFA. The initial EFA revealed an overall KMO (MSA) statistic of .874, and all item MSAs exceeded the desired value of .7 with the exception of item 16 (.466) and item 11 (.699), and $28(.675)$. All items exceeded the desirable communality value of .5 with the exception of item 1 (.434) and item 22 (.451). Seven factors were extracted with many crossed-loaded items. After several trials, the best representation of data is shown in Table 3 with four factors. As with the factor loadings for both 2014 and 2015 spring data, the factor loadings for 2015 fall data did not correspond well to the original Motivation scales, with the exception of Test Anxiety. With only four factors, both Intrinsic and Extrinsic Goal Orientation scales did not exist in this data, and similar to 2014 and 2015 spring findings. Self-Efficacy was loaded into two scales.

Table 3. Factor Loading-Motivation Scales, 2015 Fall

\begin{tabular}{lclllll}
\hline & \multicolumn{2}{c}{ Factors } & & \multicolumn{3}{c}{ Factors } \\
\cline { 2 - 3 } \cline { 5 - 6 } Item & $\mathbf{1}$ & $\mathbf{2}$ & & Item & $\mathbf{3}$ & $\mathbf{4}$ \\
\hline M23_TV & .884 & & & M5_SE & .879 & \\
M27_TV & .862 & & & M31_SE & .862 & \\
M26_TV & .805 & & & M21_SE & .862 & \\
M17_TV & .778 & & & M20_SE & .702 & \\
M4_TV & .676 & & & M6_SE & & .929 \\
M10_TV & .652 & & & M15_SE & & .921 \\
\hline M28_TA & & .825 & & M18_CB & & .551 \\
M19_TA & & .821 & & M29_SE & & .533 \\
M3_TA & & .756 & & M12_SE & & .450 \\
M8_TA & & .753 & & & & \\
M14_TA & & .674 & & & & \\
\hline
\end{tabular}

Motivation Section Confirmatory Factor Analysis

For each of the final EFAs that best represented the three iterations of data collected, a path model was created. According to Hair et al., (2010), the characteristics of a good fit include a CFI of above .90, a GFI of above .90, and a RMSEA (root mean square error of approximation) of below .07. After a path model was created, a convergent validity test, then, was conducted. Convergent validity shows items in the same motivation scale were correlated. There were two tests for convergent validity. The first was to test if the unstandardized regression weights (path coefficients) were statistically significant. The second was to test if the factor loadings (standardized regression weights) were .5 or higher. Items that violate these are removed and a CFA was performed. To test discriminant validity, the comparison of root average variance explained and inter-scale correlation was produced for the model. If a root average variance explained was larger than correlations in the same row and column in the table, the scale exhibited discriminant validity.

2014 Final Motivation Scales. The final model consisted of four items in Test Anxiety scale (items 3, 8, 18, 19), seven items in Task value scale (items 4, 10, 17, 22, 23, 26, 27), six items in Self-Efficacy scale (items 6, 12, 15, 16, 18, 19), four items in Expectancy scale (items 5, 20, 21, 31), and two items in Control Belief scale (items 9, 25). The model fit indexes included a CFI of .893, a GFI of .829, and a RMSEA of .079, all approaching the satisfactory levels. The model exhibited discriminant validity with statistically significant path coefficients and all but one factor loadings exceeded .5 , which was item 8 with a loading of .455. The scales exhibited discriminant validity with the root average variance explained larger than correlations in the same row and column, as illustrated in Table 4 . The reliability test alpha values was .797 for Test Anxiety, .911 for Task Value, .877 for Self-Efficacy, .874 for Expectancy, and .624 for Control Belief. All exceeded the desired value of .7, with the exception of Control Belief scale.

Table 4. Comparison of Root Average Variance Explained and Inter-Scale Correlations, Motivation Scales, 2014

\begin{tabular}{lrrrrr}
\hline & Test Anxiety & Task Value & Self-Efficacy & Expectancy & Control Belief \\
\hline Test Anxiety & 0.717 & & & & \\
\hline Task Value & 0.036 & 0.771 & & & \\
\hline Self-Efficacy & -0.197 & 0.676 & 0.737 & & \\
\hline Expectancy & -0.267 & 0.594 & 0.625 & 0.796 & \\
\hline Control Belief & -0.037 & 0.595 & 0.563 & 0.482 & 0.675 \\
\hline
\end{tabular}




\section{Issues in Information Systems}

Volume 18, Issue 3, pp. 149-160, 2017

2015 Spring Scales. For the Motivation data collected in 2015 spring, the model consisted of five items in Test Anxiety scale (items 3, 8, 14, 19, 28), five items in Task Value scale (items, 17, 22, 23, 26, 27), three items in SelfEfficacy scale (items, 6, 12, 15), five items in Expectancy scale (5, 20, 12, 29, 31), and two items in Control Belief scale (items 9, 25). The model fit indexes included a CFI of .873, a GFI of .844, and a RMSEA of .084. The fit indexes of this 2015 model were approaching the desired values. The model exhibited discriminant validity with statistically significant path coefficients and all but one factor loadings exceeded .5. Item 2 had a loading of .417. As illustrated in Table 5, the scales exhibited discriminant validity with the root average variance explained larger than correlations in the same row and column. Most Cronbach's alpha met the desired .7: Self-Efficacy (.779), Task Value (.869), Expectancy (.843), and Test Anxiety (.825). The only scale that had a low alpha value was Control Belief (.599).

Table 5. Comparison of Root Average Variance Explained and Inter-Scale Correlations, Motivation, 2015 Spring

\begin{tabular}{lrrrrr}
\hline & Self-Efficacy & Task Value & Expectancy & Test Anxiety & Control Belief \\
\hline Self-Efficacy & 0.741 & & & & \\
\hline Task Value & 0.333 & 0.757 & & & \\
\hline Expectancy & 0.714 & 0.502 & 0.720 & & \\
\hline Test Anxiety & -0.088 & 0.263 & -0.152 & 0.700 & \\
\hline Control Belief & 0.421 & 0.524 & 0.524 & -0.088 & 0.675 \\
\hline
\end{tabular}

2015 Fall Scales. The model consisted of only four scales with four items in Expectancy (items 5, 20, 21, 31), five items in Task Value (items 4, 10, 17, 23, 26, 27), five items in Test Anxiety (items, 3, 8, 14, 19, 28), and five items in Self-Efficacy (items 1, 12,15, 18, 29), with a GFI of .864, a CFI of .899, and a RMSEA of .076. These indexes were approaching the satisfactory fit criteria. Both convergent validity tests were satisfied with all path coefficients being statistically significant and all items had satisfactory factor loadings of higher than .5. Table 6 shows that all Motivation scales exhibited discriminant validity. Cronbach's Alpha was calculated for each of the scales. All alpha met the desired .7: Expectancy (.852), Task Value (.869), Test Anxiety (.825), and Self-Efficacy (.835).

Table 6. Comparison of the Root Average Variance Explained and Inter-Scale Correlation for Motivation, 2015 Fall

\begin{tabular}{lcccr}
\hline & Expectancy & Task Value & Text Anxiety & Self-Efficacy \\
\hline Expectancy & 0.768 & & & \\
\hline Task Value & 0.576 & 0.727 & & \\
\hline Test Anxiety & -0.176 & 0.029 & 0.699 & \\
\hline Self-Efficacy & 0.695 & 0.701 & -0.041 & 0.709 \\
\hline
\end{tabular}

\section{Learning Strategies Section Exploratory Factor Analysis}

Learning Strategy subscales were abbreviated in tables: Rehearsal (Rhrsl), Elaboration (Elb), Organization (Org), Critical Thinking (CT), Metacognitive Self-Regulation (Meta), Time and Study Environment (Time), Effort Regulation (ER), Peer Learning (PeerL), and Help Seeking (Help). Reverse-coded items were indicated with a 'r.'

2015 Spring EFA. The initial EFA revealed an overall KMO (MSA) statistic of .872, and all item MSAs exceeded the desired value of .7 with the exception of item 2 (.691) and item 9 (.601). All items exceeded the desirable communality value of .5 with the exception of item 5 (.488) and item 23 (.445). Ten factors were extracted with many crossed-loaded items. After several trials, the EFA that best represented the data had five factors, as illustrated in Table 7. The factor loadings for 2015 spring data did not correspond well to the original Learning Strategies scales. 
Table 7. Factor Loading for Learning Strategies Scales, 2015 Spring

\begin{tabular}{|c|c|c|c|c|c|c|}
\hline \multirow[b]{2}{*}{ Item } & \multicolumn{2}{|c|}{ Factor } & \multirow[b]{2}{*}{ Item } & \multicolumn{3}{|c|}{ Factor } \\
\hline & 1 & 2 & & 3 & 4 & 5 \\
\hline L42_Time & .890 & & L49r_Time & .713 & & \\
\hline L43-ER & .798 & & L46r Time & .709 & & \\
\hline L50_Elb & .782 & & L29r_ER & .687 & & \\
\hline L38_Elb & .777 & & L6r_ĒER & .672 & & \\
\hline L45_Meta & .776 & & L26r_Meta & .670 & & \\
\hline L28_Rhral & .738 & & L1_Org & & .734 & \\
\hline L10_Meta & .737 & & L32_Org & & .707 & \\
\hline L37_Help & .687 & & L47_Meta & & .683 & \\
\hline L17_ER & .678 & & L41_Rhrsl & & .572 & \\
\hline L33_Elb & .664 & & L4_Time & & & .879 \\
\hline L22_Elb & .645 & & L19_PeerL & & & .523 \\
\hline L31_Elb & .599 & & & & & \\
\hline L16_CT & & .827 & & & & \\
\hline L24_Meta & & .800 & & & & \\
\hline L35_CT & & .749 & & & & \\
\hline L27_Rhrsl & & .489 & & & & \\
\hline
\end{tabular}

2015 Fall EFA. The initial EFA revealed an overall KMO (MSA) statistic of .880, and all item MSAs exceeded the desired value of .7 with the exception of item $2(.691)$ and item 9 (.693). Thirteen items did not meet the desirable communality value of .5. Nine factors were extracted with many crossed-loaded items. After several trials, the EFA that best represented the data had five factors, as illustrated in Table 8. The factor loadings for 2015 spring data did not correspond well to the original Learning Strategies scales. Many items did not have communalities of .5 or higher, but they were all greater than .4. These were item 1 (.451), item 2 (.473), item 4 (.486), item 6 (.498), item $10(.462)$, item 21 (.496) item 28 (.452), item 29 (.426), item 40 (.441), item 46 (.463), item 47 (.457), and item $50(.450)$.

Table 8. Factor Loading for Learning Strategies Scales, 2015 Fall

\begin{tabular}{|c|c|c|c|c|c|c|}
\hline \multirow[b]{2}{*}{ Item } & \multicolumn{2}{|c|}{ Factor } & \multirow[b]{2}{*}{ Item } & \multicolumn{3}{|c|}{ Factor } \\
\hline & 1 & 2 & & 3 & 4 & 5 \\
\hline L35 CT & .786 & & L10 Meta & .660 & & \\
\hline L27 Rhrsl & .781 & & L28 $\mathrm{Rhrsl}$ & .648 & & \\
\hline L24_Meta & .739 & & L38_Elb & .605 & & \\
\hline $\mathrm{L} 20 \_\mathrm{CT}$ & .728 & & L50_Elb & .598 & & \\
\hline L41 Rhrsl & .700 & & L43 ER & .579 & & \\
\hline L16-CT & .682 & & L40- $\mathrm{CT}$ & .550 & & \\
\hline L36-ER & .675 & & L45 ${ }^{-}$Meta & .534 & & \\
\hline L49r Time & & .743 & L34 Time & & .745 & \\
\hline L2r Meta & & .672 & L12- Time & & .675 & \\
\hline L45r Time & & .663 & L4 T̄ime & & .644 & \\
\hline L6r $\bar{E} R$ & & .654 & L1 ${ }^{-}$Org & & .542 & \\
\hline L21 $\bar{r}$ Time & & .600 & L4⿳亠口冋 Meta & & .505 & \\
\hline L29r_ER & & .568 & L14_PeerL & & & .742 \\
\hline L26r Meta & & .557 & L44 Help & & & .712 \\
\hline & & & L37- Help & & & .708 \\
\hline
\end{tabular}

\section{Learning Strategies Section Confirmatory Factor Analysis}

Similar to the Motivation data, the EFAs of the two iterations of data collection were subjected to CFA, convergent validity test, and discriminant validity test.

2015 Spring Scales. The initial path model revealed a non-significant path coefficient for item 19 ( $\mathrm{p}=.511$ ), so this item had to be removed. With only two items in Factor 5 (items 4 and 19), the removal of item 19 caused the removal 


\section{Issues in Information Systems}

Volume 18, Issue 3, pp. 149-160, 2017

of the factor because a factor must have the minimum of two items; therefore, the final model consisted only four factors. There were 12 items in Factor 1 (items, 10, 17, 22, 2 8, 31, 33, 37, 38, 42, 43, 45, 50), 4 items in Factor 2 (items, 16, 24, 27, 35), 4 items in Factor 3 (items 6, 26, 29, 46, 49), and 4 items in Factor 4 (items 1, 32, 41, 47). The CFI was .852, the GFI was .813, and the RMSEA was .077, all approaching the desired values. The scales satisfied both convergent validity tests with all path coefficients being statistically significant and all but two items had satisfactory factor loadings: item 26 (.474) and item 47 (.451). In addition, all five scales exhibited discriminant validity. Table 9 shows the comparison of root average variance and inter-scale correlations for the final Learning Strategies Scales. All alpha values, with the exception of Factor 4 exceeded .7: Factor 3 (.731), Factor 1 (.928), Factor 2 (.783), and Factor 4 (.685).

Table 9. Comparison of the Root Average Variance Explained and Inter-Scale Correlation for Learning Strategies Scales, 2015 Spring

\begin{tabular}{lcccc}
\hline & Factor 3 & Factor 1 & Factor 2 & Factor 4 \\
\hline Factor 3 & 0.599 & & & \\
\hline Factor 1 & 0.220 & 0.721 & & \\
\hline Factor 2 & -0.179 & 0.453 & 0.690 & \\
\hline Factor 4 & -0.241 & 0.342 & 0.580 & 0.600 \\
\hline
\end{tabular}

2015 Fall Scales. This model consisted of 5 factors and 27 items. Factor 1 had seven items (items 16, 20, 24, 27, 35, 36, 41), Factor 2 has seven items (2, 6, 21, 26, 29, 46, 49), Factor 3 had five items (items 10, 28, 38, 45, 50), Factor 4 had five items $(1,4,12,34,47)$, and Factor 5 had three items $(14,37,44)$. The GFI for this model was .866 , the CFI was .877, and the RMSEA was .059. Both GFI and CIF were close to the designed .9, and the RMSEA was below the desired .07 . The scales also satisfied both convergent validity tests with all path coefficients being statistically significant and all items had satisfactory factor loadings of higher than .5 , and all five scales exhibited discriminant validity as well. Table 10 shows the comparison of root average variance and inter-scale correlations for the final Learning Strategies Scales. All alpha values, with the exception of Factor 5 exceeded .7: Factor 4 (.738), Factor 1 (.888), Factor 2(.775), Factor 3 (.741), and Factor 5 (.688).

Table 10. Comparison of Root Average Variance Explained and Inter-Scale Correlation for Learning Strategies Scales, 2015 Fall

\begin{tabular}{lrrrrr}
\hline & Factor 4 & Factor 1 & Factor 2 & Factor 3 & Factor 5 \\
\hline Factor 4 & 0.601 & & & & \\
\hline Factor 1 & 0.518 & 0.730 & & & \\
\hline Factor 2 & 0.194 & -0.225 & 0.576 & & \\
\hline Factor 3 & 0.593 & 0.574 & 0.115 & 0.606 & \\
\hline Factor 5 & 0.447 & 0.498 & -0.184 & 0.563 & 0.653 \\
\hline
\end{tabular}

\section{DISCUSSION}

Multiple iterations of data collections revealed that the most stable scale was Text Anxiety. Four of the items in this construct were the same across three iterations of data collections, as shown in Table 11. Items that were common in all three iterations of data analyses were highlighted in bold for ease of identification. Task Value scale was fairly stable as well. Four of the items in this construct were the same across three rounds of data analyses. One item from Intrinsic Goal Orientation was loaded in this scale; interestingly, the same item, item 22, was loaded into Task Values scale in both 2014 and 2015 spring analyses. Cook, Thompson, and Thomas (2011) reported similar finding that Intrinsic Goal items clustered with Task Values in their study. 
Table 11. Motivation Scale and Item Comparison

\begin{tabular}{|c|c|c|c|}
\hline & 2014 & 2015 spring & 2015 Fall \\
\hline Scale & Item \# & Item \# & Item \# \\
\hline Test anxiety & $3,8,19,28$ & $\mathbf{3}, \mathbf{8}, 14, \mathbf{1 9}, \mathbf{2 8}$ & $3,8,14,19,28$ \\
\hline Task value & $4,10,17,22, \mathbf{2 3}, \mathbf{2 6}, 27$ & $17,22, \mathbf{2 3}, \mathbf{2 6}, 27$ & $4,10,17,23,26,27$ \\
\hline Self-efficacy & $\mathbf{6}, \mathbf{1 2}, \mathbf{1 5}, 16,18,29$ & $6,12,15$ & $\mathbf{6}, \mathbf{1 2}, \mathbf{1 5}, 18,29$ \\
\hline Expectancy (new) & $5,20,21,31$ & $\mathbf{5}, \mathbf{2 0}, \mathbf{2 1}, 29, \mathbf{3 1}$ & $5,20,21,31$ \\
\hline Control belief & 9,25 & 9,25 & \\
\hline
\end{tabular}

The eight items in Self-Efficacy scale were loaded in two different scales in all three wave of analyses. In 2014, one item from Intrinsic Goal and one item from Control Belief were loaded with four items from Self-Efficacy, and in 2015 fall, one items from Control Belief scale was loaded with four items from Self-Efficacy. Cook et al. (2011) reported similar findings that Intrinsic Goal items clustered with Task Value and Self-Efficacy and that Control Belief clustered with Self-Efficacy. As aforementioned, four of the original Self-Efficacy items were loaded into a new factor across all three iterations of data analyses. It was decided to label the new factor as 'Expectancy.' The Control belief scale was consistent only between 2014 and 2015 spring analyses and did not exist in the 2015 fall version. In addition, the only item in the original Intrinsic Goal scale remained in both 2014 and 2015 spring versions was item 22, but this item was clustered in the Task Value scale. Item 16 in the original Intrinsic Goal scale remanded in the 2014 model but was clustered in the Self-Efficacy scale. All items in the original Extrinsic Goal scale were deleted in all three cycles of EFA and CFA analyses in order to obtain the best solutions. Similar constructs were found in Vaculíkova's third round of validation study (2016), in which the Motivation section had only three scales: Self-Efficacy, Task Value, and Test Anxiety. Furthermore, some items in this current study were in the same construct in Vaculíkova's study. For example, items 4, 17, 23, and 26 were in the Task Value scale in both studies, although Vaculíkova used different numbers for these items. Items 14, 19, and 28 were all loaded in the same Test Anxiety scale in both studies, and items 6 and 29 were loaded in Self-Efficacy scale in both studies as well. Similar subscales were found in the study conducted by Hilpert et al. (2013). They identified a three-factor model with six sub-scales, including selfefficacy, control of learning, intrinsic goals, task value, metacognitive regulation, and effort regulation.

Vaculíkova's study (2016) involved "544 university students enrolled in a traditional face-to-face course delivery format" (p. 37), but the subjects of the course(s) were not available. Students enrolled in introductory to physical geology courses participated in Hilpert et al.'s study (2013), while medicine residents participated in Cook et al.'s study. With participants from a wide range of subject areas, the similar findings from this and other studies suggested that the findings were not restricted in computer-related courses. The construct issues in the Motivation section of the MSLQ seemed to cross different subject areas.

Two iterations of data analyses for the Learning Strategies section revealed two models with constructs that are different from those in the original MSLQ. However, there was item consistency between the two iterations of analyses. As illustrated in Table 12, five items in Factor 1 in 2015 spring model and Factor 3 in 2015 fall model were the same items, although they were from three different scales in the original MSLQ, including Metacognition SelfRegulation, Elaboration, and Rehearsal. Similarly, four of the items in Factor 2 in 2015 spring and in Factor 1 in 2015 fall were the same items, but they were originally in Metacognition Self-Regulation, Critical Thinking, Rehearsal, and Elaboration. The three items in Factor 5 in 2015 fall was from the original Peer Learning and Help Seeking scales. Other researchers had similar findings. For example, Rao and Sachs (1999) found that many items in elaboration, rehearsal, and metacognitive self-regulation were not distinguishable and combined them as a Strategy Use scale. Credé and Phillips (2011) found that scores on peer learning and help seeking were strongly related that these two factors might be the same construct. 
Table 12. Learning Strategies comparison

\begin{tabular}{|c|c|c|c|}
\hline & 2015 spring & & 2015 Fall \\
\hline Factor \# & Item \# & Factor \# & Item \# \\
\hline Factor 1 & $\mathbf{1 0}, 17,22, \mathbf{2 8}, 31,33,37, \mathbf{3 8}, 42,43, \mathbf{4 5}, \mathbf{5 0}$ & Factor 3 & $10,28,38,45,50$ \\
\hline Factor 2 & $16,24,27,35$ & Factor 1 & $\mathbf{1 6}, 20, \mathbf{2 4}, \mathbf{2 7}, \mathbf{3 5}, 36,41$ \\
\hline Factor 3 & $6 r, 26 r, 29 r, 46 r, 49 r$ & Factor 2 & $2 r, 6 r, 21 r, 26 r, 29 r, 46 r, 49 r$ \\
\hline \multirow[t]{2}{*}{ Factor 4} & $\mathbf{1}, 32,41, \mathbf{4 7}$ & Factor 4 & $\mathbf{1}, 4,12,34, \mathbf{4 7}$ \\
\hline & & Factor 5 & $14,37,44$ \\
\hline
\end{tabular}

With items in every new scale were from various scales in the original MSLQ, re-labeling the new scales was warranted. After reading each of the statements and determining similarities, it was decided to rename all the new scales. The new scale labels are shown in Table 13. In this current study, the new Self-Governance scale consisted of only reverse-coded items. This was consistent with the findings revealed in Rao and Sachs' study (1999). They found that all reverse-coded items formed a separate factor. These findings suggested that reversed-coded item might need to be reworded or eliminated from future research.

Table 13. New Learning Strategies Scale Labels and Items

\begin{tabular}{|c|c|c|}
\hline & 2015 spring & 2015 Fall \\
\hline Factor \# & Item \# & Item \# \\
\hline Strategic Thinking & $10,17,22,28,31,33,37,38,42,43,45,50$ & $10,28,38,45,50$ \\
\hline Higher-Order Organization & $16,24,27,35$ & $16,20,24,27,35,36,41$ \\
\hline Self-Governance & $6 r, 26 r, 29 r, 46 r, 49 r$ & $2 r, 6 r, 21 r, 26 r, 29 r, 46 r, 49 r$ \\
\hline Productivity Strategies & $1,32,41,47$ & $1,4,12,34,47$ \\
\hline Collaborative Learning & & $14,37,44$ \\
\hline
\end{tabular}

Similar to the findings in the Motivation section, the consistent findings of this and prior studies suggested that the construct issues in the original Learning Strategies were not subject-specific.

\section{CONCLUSIONS}

With three iterations of data collection to validate constructs in the Motivation section and two iterations of data collection to validate constructs in the Learning Strategies section, this study found constructs that were not consistent with those in the original MSLQ. For example, none of the three iterations of data collection supported the existence of Intrinsic and Extrinsic Goal Motivation constructs. In addition, the findings in this and prior studies suggested that there was more than one construct in the Self-Efficacy scale and that some items in this scale belong to an Expectation construct. Interestingly, the most consistent construct in the Motivation section was Test Anxiety.

Different issues arose in the Learning Strategies section. The findings revealed two main issues. First, many scales were not distinguishable, including elaboration, rehearsal, metacognitive self-regulation, and effort regulation. Second, all reverse-coded items formed a separate scale. This is an interesting phenomenon because items in this scale were from different original scales. Clearly, there is a need to investigate this in future research. In addition, Help seeking and peer learning didn't exist in 2015 spring data and were combined in 2015 fall data.

This and recent research revealed common construct issues with MSLQ. Since the participants of these studies were from a wide range of subject areas, the issues were not isolated only in information systems or computer-related subjects. It is recommended that future research using MSLQ include relevant validity tests prior to other data analyses to reveal any construct issues, if any. 


\section{REFERENCES}

Butler, D. L., \& Winne, P. H. (1995). Feedback and self-regulated learning: A theoretical synthesis. Review of Educational Research, 65, 245-281.

Chalupa, M., Chen, C., \& Charles, T. (2001). An analysis of college students' motivation and learning strategies in computer courses: A cognitive view. Delta Pi Epsilon Journal, 43(4), 185-199.

Chen, C. (2002). Self-regulated learning strategies and achievement in an introduction to information systems course. Information Technology, Learning and Performance Journal, 20(1), 11-25.

Cook, D. A., Thompson, W. G., \& Thomas, K. G. (2011). The motivated strategies for learning questionnaire: score validity among medicine residents. Medical education, 45(12), 1230-1240.

Credé, M., \& Phillips, L. A. (2011). A meta-analytic review of the Motivated Strategies for Learning Questionnaire. Learning and Individual Differences, 21(4), 337-346.

Cronbach, L. J., \& Shavelson, R. J. (2004). My current thoughts on coefficient alpha and successor procedures. Educational and Psychological Measurement, 64(3), 391-418. doi: 10.1177/0013164404266386

Dobrovolny, J. (2006). How adults learn from self-paced, technology-based corporate training: New focus for learners, new focus for designers. Distance Education, 27(2), 155-170.

Dunn, K. E., Lo, W. J., Mulvenon, S. W., \& Sutcliffe, R. (2012). Revisiting the motivated strategies for learning questionnaire: A theoretical and statistical reevaluation of the metacognitive self-regulation and effort regulation subscales. Educational and Psychological Measurement, 72(2), 312-331.

Hair, J. F., Black, W. C., Babin, B. J., Anderson, R. E., \& Tatham, R. (2010). Multivariate Data Analysis. Upper Saddle River, New Jersey: Pearson Education.

Hilpert, J., Stemien, J., van der Hoeven Kraft, K., \& Husman, J. (2013). Evidence for the latent factor structure of the MSLQ: A new conceptualization of an established questionnaire. SAGE Open. Retrieve from http://classic.sgo.sagepub.com/content/3/4/2158244013510305.short

Kane, M. (2001). Current concerns in validity theory. Journal of Educational Measurement, 38, 319-342.

Malpass, J. R., O’Neil, H. F., \& Hocevar, D. (1999). Self-regulation, goal orientation, self-efficacy, worry, and highstakes math achievement for mathematically gifted high school students. Roeper Review, 21, 281-289.

Niemczyk, M. C., \& Savenye, W. C. (2001). The relationship of student motivation and self-regulated learning strategies to performance in an undergraduate computer literacy course. (ED 470107)

Pintrich, P. R. (1995). Understanding self-regulated learning. In P. R Pintrich (Ed.), Understanding self-regulated learning (pp. 3-12). San Francisco, CA: Jossey-Bass Publishers.

Pintrich, P. R. (2004). A conceptual framework for assessing motivation and self-regulated learning in college students. Educational Psychology Review, 16(4), 385-407.

Pintrich, P. R., Smith, D., Garcia, T., \& McKeachie, W. J. (1991). A manual for the use of the motivated strategies for learning questionnaire. Ann Arbor, MI: University of Michigan.

Rao, N., \& Sachs, J. (1999). Confirmatory factor analysis of the Chinese version of the motivated strategies for learning questionnaire. Educational and Psychological Measurement, 59(6), 1016-1029. 


\section{Issues in Information Systems}

Volume 18, Issue 3, pp. 149-160, 2017

Vaculíkova, J. (2016). The Third Round of the Czech Validation of the Motivated Strategies for Learning Questionnaire (MSLQ). International Education Studies, 9(7), 35.

Wolters, C. A., \& Pintrich, P. R. (1998). Contextual differences in student motivation and self-regulated learning in mathematics, English, and social studies classrooms. Instructional Science, 26, 27-47.

Zimmerman, B. J. (2001). Theories of self-regulated learning and academic achievement: An overview and analysis. In B. J. Zimmerman \& D. H. Schunk (Eds.), Self-regulated learning and academic achievement: Theoretical perspectives ( $2^{\text {nd }}$ ed., pp. 1-37). Hillsdale, NJ: Erlbaum.

Zimmerman, B. J., \& Risemberg R. (1997). Self-regulatory dimensions of academic learning and motivation. In G. D. Phye (Ed.), Handbook of academic learning: Construction of knowledge (pp. 105-125). San Diego, CA: Academic Press. 